\title{
A Subdivision Based Iterative Collocation Algorithm for Nonlinear Third-Order Boundary Value Problems
}

\author{
Syeda Tehmina Ejaz and Ghulam Mustafa \\ Department of Mathematics, The Islamia University of Bahawalpur, Punjab 63100, Pakistan \\ Correspondence should be addressed to Ghulam Mustafa; ghulam.mustafa@iub.edu.pk
}

Received 8 February 2016; Accepted 11 May 2016

Academic Editor: Xiao-Jun Yang

Copyright (C) 2016 S. T. Ejaz and G. Mustafa. This is an open access article distributed under the Creative Commons Attribution License, which permits unrestricted use, distribution, and reproduction in any medium, provided the original work is properly cited.

We construct an algorithm for the numerical solution of nonlinear third-order boundary value problems. This algorithm is based on eight-point binary subdivision scheme. Proposed algorithm is stable and convergent and gives more accurate results than fourthdegree B-spline algorithm.

\section{Introduction}

Many problems in physics, chemistry, and engineering science are demonstrated mathematically by third-order boundary value problems. These boundary value problems can be found in different areas of applied mathematics and physics as, in the deflection of a curved beam having a constant or varying cross section, a three-layer beam, electromagnetic waves, or gravity driven flows. Third-order boundary value problems were discussed in many papers in recent years. Different types of techniques have been used to study such problems: finite difference method, spline method, Haar wavelets method, Adomian decomposition, modified Adomian decomposition method (MADM) shooting technique via Newton method, He's homotopy perturbation method, and so forth. Haq et al. [1] studied the Haar wavelets method to solve the third-order boundary value problem. A modified form of Adomian decomposition method is applied to construct the numerical solution for solving third-order boundary value problems proposed by Duan and Rach [2] and Hasan [3]. Abdullah et al. [4] solved the third-order boundary value problem directly using the fourth-order twopoint block method adapted with the shooting technique via Newton method. Caglar et al. [5] solved third-order linear and nonlinear boundary value problems by using fourthdegree B-splines. Their algorithm has first-order accuracy. A new algorithm for solving the general nonlinear third-order differential equation is developed by [6] using shifted JacobiGauss collocation spectral method.

For finite differences methods, only discrete approximate values of the unknown $y(x)$ can be obtained. We need further data processing techniques to get accurate fitted curve to data. For spline interpolation or approximation methods the unknown function $y(x)$ is assumed to be piecewise polynomial which in turn requires at least piecewise higher order differentiability of the function $f(x, y, u, v)$.

To overcome the above disadvantages, $\mathrm{Qu}$ and Agarwal $[7,8]$ introduced the subdivision based algorithm for the solution of two-point second-order boundary value problems. Mustafa and Ejaz [9] solved linear third-order boundary value problems by using subdivision technique. Ejaz et al. [10] solved two-point fourth-order linear boundary value problem by subdivision based method. Higher order linear and nonlinear problems are not solved by subdivision techniques until now. This motivates us to solve nonlinear third-order boundary value problems by subdivision schemes based collocation iterative algorithms.

An outline of the paper is as follows. In Section 2, some results about existence and uniqueness of the solution of third-order boundary value problem are given. In Section 3, subdivision algorithm, basis function, and their derivatives are briefed. In Section 4, subdivision based iterative algorithm for the solution of nonlinear third-order BVPs using the derivatives of basis functions is formulated. Convergence 
of the proposed algorithm is also discussed in this section. Error analysis is given in Section 5. Numerical examples illustrating the usefulness of our proposed algorithm are given in Section 6.

\section{Existence and Uniqueness of the Solution}

In this section, we present some results about the existence and uniqueness of the solution of third-order nonlinear boundary value problems. The details of these results can be found in [11].

The general third-order nonlinear boundary value problem can be prescribed as

$$
y^{\prime \prime \prime}=f\left(x, y, y^{\prime}, y^{\prime \prime}\right)
$$

with boundary conditions defined as

$$
\begin{aligned}
& y(0)=\alpha_{1}, \\
& y^{\prime}(0)=\alpha_{2}, \\
& y(1)=\alpha_{3},
\end{aligned}
$$

where $\alpha_{i}, i=1,2,3$ are constants.

Proposition 1. If the function $f\left(x, y, y^{\prime}, y^{\prime \prime}\right)$ is continuous and satisfies the following uniform Lipschitz condition:

$$
\begin{aligned}
& \left|f\left(x, y, y^{\prime}, y^{\prime \prime}\right)-f\left(x, \widetilde{y}, \widetilde{y^{\prime}}, \widetilde{y^{\prime \prime}}\right)\right| \\
& \leq M_{0}|y-\tilde{y}|+M_{1}\left|y^{\prime}-\widetilde{y^{\prime}}\right|+M_{2}\left|y^{\prime \prime}-\widetilde{y^{\prime \prime}}\right| \\
& \forall\left(x, y, y^{\prime}, y^{\prime \prime}\right),\left(x, \widetilde{y}, \widetilde{y^{\prime}}, \widetilde{y^{\prime \prime}}\right) \in[a, b] \times R^{3},
\end{aligned}
$$

where the constants $M_{0}, M_{1}$, and $M_{2}$ satisfy

$$
\frac{2}{81} M_{0}(b-a)^{3}+\frac{1}{6} M_{1}(b-a)^{2}+\frac{2}{3} M_{2}(b-a)<1
$$

or

$$
\frac{3}{160} M_{0}(b-a)^{3}+\frac{17}{150} M_{1}(b-a)^{2}+\frac{2}{3} M_{2}(b-a)<1
$$

then the boundary value problem has one and only one solution:

$$
\begin{aligned}
y^{\prime \prime \prime}= & f\left(x, y, y^{\prime}, y^{\prime \prime}\right), \\
& a \leq x \leq b, y(a)=y_{1}, y^{\prime}(a)=y_{2}, y(b)=y_{3} .
\end{aligned}
$$

The existence and uniqueness of the differential equation (1) with boundary conditions at two or three points are presented in [11].

Remark 2. Throughout this paper the function $f\left(x, y, y^{\prime}, y^{\prime \prime}\right)$ satisfies Lipschitz conditions (3) along with condition (4)(6). So the existence and uniqueness of the solutions of (1) are guaranteed.

\section{Subdivision Scheme and Basis Function}

In this section, we define binary subdivision algorithm and their basis function that are used to construct the approximate solutions of (1).

3.1. Interpolating Subdivision Scheme. We consider the following 8-point binary interpolating subdivision scheme introduced in $[12,13]$

$$
\begin{aligned}
p_{2 i}^{k+1}= & p_{i}^{k}, \\
p_{2 i+1}^{k+1}= & \frac{1225}{2048}\left(p_{i}^{k}+p_{i+1}^{k}\right)-\frac{245}{2048}\left(p_{i-1}^{k}+p_{i+2}^{k}\right) \\
& +\frac{49}{2048}\left(p_{i-2}^{k}+p_{i+3}^{k}\right) \\
& -\frac{5}{2048}\left(p_{i-3}^{k}+p_{i+4}^{k}\right),
\end{aligned}
$$

where $p_{i}^{k}$ and $p_{i}^{k+1}$ are points at $k$ th and $(k+1)$ th iterative level. Scheme $(7)$ is $C^{3}$-continuous and support length $(-7,7)$ with 8th-order approximation.

3.2. Basis Function and Their Derivatives. The basis function is the limit function resulting from cardinal data, where all vertices of the polygon have value zero except for one. Let $g(x), x \in \mathbb{R}$ be the fundamental solution of (7) that satisfies the two-scale equation:

$$
\begin{aligned}
& g(x)=g(2 x)+\frac{1}{2048}[1225\{g(2 x-1)+g(2 x+1)\} \\
& -245\{g(2 x-3)+g(2 x+3)\} \\
& +49\{g(2 x-5)+g(2 x+5)\} \\
& \quad-5\{g(2 x-7)+g(2 x+7)\}], \quad x \in \mathbb{R}, \\
& g(x) \in C^{3}, \\
& g(x)=0,
\end{aligned}
$$$$
\text { if } x \notin[-6,6] \text {, }
$$$$
g(i)=\delta_{0}, \quad i \in \mathbb{Z}
$$

Proposition 3. The fundamental solution is three times continuously differentiable over the interval $[-6,6]$. Its derivatives at integers are given by

$$
\begin{aligned}
g^{\prime}(i) & =2 \operatorname{sign}(i) E_{|i|}^{T} \eta_{1}, \\
g^{\prime \prime}(i) & =2^{2} E_{|i|}^{T} \eta_{2}, \\
g^{\prime \prime \prime}(i) & =2^{3} \operatorname{sign}(i) E_{|i|}^{T} \eta_{3},
\end{aligned}
$$


where

$$
\operatorname{sgn}(t)= \begin{cases}-1, & t<0 \\ 0, & t=0 \\ 1, & t>0\end{cases}
$$

and $E_{t}$ 's for $0 \leq t \leq 6$ are defined below

$$
\begin{aligned}
& E_{t}=\left(e_{6 t}, e_{5 t}, e_{4 t}, e_{3 t}, e_{2 t}, e_{1 t}, e_{0 t}, e_{-1 t}, e_{-2 t}, e_{-3 t}, e_{-4 t}, e_{-5 t},\right. \\
& \left.e_{-6 t}\right)^{T}
\end{aligned}
$$

where

$$
e_{i t}= \begin{cases}1, & i=t \\ 0, & i \neq t\end{cases}
$$

and $\eta_{j}, 1 \leq j \leq 3$, are defined in [9].

Furthermore, the numeric values of first, second, and third derivatives of $g(i)$ at $i \in[-6,6]$ are

$$
\begin{aligned}
& g^{\prime}(0)=0 \\
& g^{\prime}( \pm 1)=\mp \frac{78592}{49553} \\
& g^{\prime}( \pm 2)= \pm \frac{76113}{198212} \\
& g^{\prime}( \pm 3)=\mp \frac{3328}{49553} \\
& g^{\prime}( \pm 4)= \pm \frac{2645}{594636} \\
& g^{\prime}( \pm 5)= \pm \frac{256}{743295} \\
& g^{\prime}( \pm 6)=\mp \frac{1}{594636} \\
& g^{\prime \prime}(0)=-\frac{342643}{41124} \\
& g^{\prime \prime}( \pm 4)=-\frac{60871}{2878680} \\
& g^{\prime \prime}( \pm 6)=\frac{55}{1727208} \\
& g^{\prime \prime}( \pm 1)=\frac{5704256}{1079505} \\
& g^{\prime \prime}( \pm 2)=-\frac{12053651}{8636040} \\
& 1079505
\end{aligned}
$$

$$
\begin{aligned}
& g^{\prime \prime \prime}(0)=0 \\
& g^{\prime \prime \prime}( \pm 1)=\mp \frac{292352}{117495}, \\
& g^{\prime \prime \prime}( \pm 2)= \pm \frac{3047987}{1879920}, \\
& g^{\prime \prime \prime}( \pm 3)=\mp \frac{3312}{13055}, \\
& g^{\prime \prime \prime}( \pm 4)=\mp \frac{1369}{234990}, \\
& g^{\prime \prime \prime}( \pm 5)= \pm \frac{16}{2611}, \\
& g^{\prime \prime \prime}( \pm 6)=\mp \frac{5}{41776} .
\end{aligned}
$$

The above derivative values are found by using the left eigenvectors of the subdivision process (7). The detailed description about these left eigenvectors $\eta_{j}, 1 \leq j \leq 3$, and derivatives can be found in [9].

\section{Subdivision Based Iterative Algorithm}

In this section, we describe the algorithm for the numerical solution of nonlinear boundary value problem (1).

4.1. The Collocation Algorithm. In this subsection, we construct the collocation method based on the interpolating subdivision scheme (7). Let $U(x)$ be the assumed solution of (1):

$$
U(x)=\sum_{i=-6}^{N+6} u_{i} g\left(\frac{x-x_{i}}{h}\right), \quad 0 \leqslant x \leqslant 1,
$$

where $N(\geqslant 6) \in \mathbb{Z}^{+}, h=1 / N, x_{i}=i / N=i h$, and $\left\{u_{i}\right\}$ are unknown to be determined for the solution of (1). The collocation algorithm together with the boundary conditions is defined as follows:

$$
\begin{aligned}
U^{\prime \prime \prime}\left(x_{j}\right)=f\left(x_{j}, U\left(x_{j}\right), U^{\prime}\left(x_{j}\right)\right), & \\
& j=0,1,2, \ldots, N,
\end{aligned}
$$

with the following type of boundary conditions:

$$
\begin{gathered}
U(0)=\alpha_{1}, \\
U^{\prime}(0)=\alpha_{2}, \\
U(N)=\alpha_{3},
\end{gathered}
$$

by taking the third derivative of (16) we get

$$
U^{\prime \prime \prime}(x)=\frac{1}{h^{3}} \sum_{i=-6}^{N+6} u_{i} g^{\prime \prime \prime}\left(\frac{x-x_{i}}{h}\right), \quad 0 \leqslant x \leqslant 1,
$$


using (19) into (17), we get

$$
\begin{array}{r}
\sum_{i=-6}^{N+6} u_{i} g^{\prime \prime \prime}\left(\frac{x_{j}-x_{i}}{h}\right)=h^{3} f\left(x_{j}, U\left(x_{j}\right), U^{\prime}\left(x_{j}\right)\right), \\
j=0,1,2, \ldots, N .
\end{array}
$$

This can be written as

$$
\begin{aligned}
& \sum_{i=-6}^{N+6} u_{i} g_{j-i}^{\prime \prime \prime}=h^{3} f\left(x_{j}, U\left(x_{j}\right), U^{\prime}\left(x_{j}\right)\right) \\
& j=0,1,2, \ldots, N .
\end{aligned}
$$

As we know that $g_{i}^{\prime \prime \prime}=-g_{-i}^{\prime \prime \prime}$, then above system of equations becomes

$$
\begin{aligned}
\sum_{i=-6}^{N+6}(-1) u_{i} g_{i-j}^{\prime \prime \prime}=h^{3} f\left(x_{j}, U\left(x_{j}\right), U^{\prime}\left(x_{j}\right)\right) & \\
& j=0,1,2, \ldots, N .
\end{aligned}
$$

Now we simplify the nonlinear system of (22) in the following theorems.

Theorem 4. The nonlinear system of (22) for $j=0$ becomes

$$
\sum_{i=-6}^{6}(-1) u_{i} g_{i}^{\prime \prime \prime}=h^{3} f\left(x_{0}, U\left(x_{0}\right), U^{\prime}\left(x_{0}\right)\right) \text {. }
$$

Proof. By expanding (22) for $j=0$, we get

$$
\begin{aligned}
& (-1)\left\{u_{-6} g_{-6}^{\prime \prime \prime}+u_{-5} g_{-5}^{\prime \prime \prime}+\cdots+u_{N+5} g_{N+5}^{\prime \prime \prime}\right. \\
& \left.+u_{N+6} g_{N+6}^{\prime \prime \prime}\right\}=h^{3} f\left(x_{0}, U\left(x_{0}\right), U^{\prime}\left(x_{0}\right)\right) .
\end{aligned}
$$

As we know $g^{\prime \prime \prime}(i)$ exists only for the interval for $i \in[-6,6]$ and outside the interval it will be zero. Then above equation can be written as

$$
\begin{aligned}
(-1) & \left\{u_{-6} g_{-6}^{\prime \prime \prime}+u_{-6} g_{-6}^{\prime \prime \prime}+\cdots+u_{5} g_{5}^{\prime \prime \prime}+u_{6} g_{6}^{\prime \prime \prime}\right\} \\
= & h^{3} f\left(x_{0}, U\left(x_{0}\right), U^{\prime}\left(x_{0}\right)\right) .
\end{aligned}
$$

This implies (23).

Theorem 5. For $j=1,2, \ldots, N$, the nonlinear system of (22) becomes

$$
\sum_{i=-6+j}^{6+j}(-1) u_{i} g_{i-j}^{\prime \prime \prime}=h^{3} f\left(x_{j}, U\left(x_{j}\right), U^{\prime}\left(x_{j}\right)\right) \text {. }
$$

Proof. Substituting $j=1$ in (22), it becomes

$$
\begin{aligned}
& (-1)\left\{u_{-6} g_{-7}^{\prime \prime \prime}+u_{-5} g_{-6}^{\prime \prime \prime}+\cdots+u_{7} g_{6}^{\prime \prime \prime}+\cdots\right. \\
& \left.+u_{N+6} g_{N+5}^{\prime \prime \prime}\right\}=h^{3} f\left(x_{1}, U\left(x_{1}\right), U^{\prime}\left(x_{1}\right)\right) .
\end{aligned}
$$

$g^{\prime \prime \prime}(i)$ is nonzero only for the interval for $i \in[-6,6]$ and outside the interval it will be zero. Then the above equation becomes

$$
\begin{aligned}
& (-1)\left\{u_{-5} g_{-6}^{\prime \prime \prime}+u_{-4} g_{-5}^{\prime \prime \prime}+\cdots+u_{4} g_{5}^{\prime \prime \prime}+u_{5} h_{6}^{\prime \prime \prime}\right\} \\
& =h^{3} f\left(x_{1}, U\left(x_{1}\right), U^{\prime}\left(x_{1}\right)\right) .
\end{aligned}
$$

For $j=2,(22)$ becomes

$$
\begin{aligned}
& (-1)\left\{u_{-6} g_{-8}^{\prime \prime \prime}+u_{-5} g_{-7}^{\prime \prime \prime}+u_{-4} g_{-6}^{\prime \prime \prime}+\cdots+u_{4} g_{2}^{\prime \prime \prime}\right. \\
& +u_{5} g_{3}^{\prime \prime \prime}+u_{6} g_{4}^{\prime \prime \prime}+u_{7} g_{5}^{\prime \prime \prime} u_{8} g_{6}^{\prime \prime \prime}+\cdots+u_{N+5} g_{N+3}^{\prime \prime \prime} \\
& \left.+u_{N+6} g_{N+4}^{\prime \prime \prime}\right\}=h^{3} f\left(x_{2}, U\left(x_{2}\right), U^{\prime}\left(x_{2}\right)\right) .
\end{aligned}
$$

This implies

$$
\begin{aligned}
(-1) & \left\{u_{-4} g_{-6}^{\prime \prime \prime}+u_{-3} g_{-5}^{\prime \prime \prime}+\cdots+u_{7} g_{5}^{\prime \prime \prime}+u_{8} g_{6}^{\prime \prime \prime}\right\} \\
= & h^{4} f\left(x_{2}, U\left(x_{2}\right), U^{\prime}\left(x_{2}\right)\right) .
\end{aligned}
$$

Similarly, we can find the expression for $j=3,4, \ldots, N$; that is,

$$
\begin{aligned}
& (-1)\left\{u_{-3} g_{-6}^{\prime \prime \prime}+u_{-4} g_{-5}^{\prime \prime \prime}+\cdots+u_{8} g_{5}^{\prime \prime \prime}+u_{9} g_{6}^{\prime \prime \prime}\right\} \\
& =h^{3} f\left(x_{3}, U\left(x_{3}\right), U^{\prime}\left(x_{3}\right)\right), \\
& (-1)\left\{u_{-2} g_{-6}^{\prime \prime \prime}+u_{-1} g_{-5}^{\prime \prime \prime}+\cdots+u_{9} g_{5}^{\prime \prime \prime}+u_{10} g_{6}^{\prime \prime \prime}\right\} \\
& =h^{3} f\left(x_{4}, U\left(x_{4}\right), U^{\prime}\left(x_{4}\right)\right), \\
& \quad \vdots \\
& (-1)\left\{u_{N-6} g_{-6}^{\prime \prime \prime}+u_{N-5} g_{-5}^{\prime \prime \prime}+\cdots+u_{N+5} g_{5}^{\prime \prime \prime}+u_{N+6} g_{6}^{\prime \prime \prime}\right\} \\
& =h^{3} f\left(x_{N}, U\left(x_{N}\right), U^{\prime}\left(x_{N}\right)\right) .
\end{aligned}
$$

Hence, by combining (28), (30), and (31) we get (26).

4.2. Unstable Nonlinear System. The nonlinear system of (22) is equivalent to the following nonlinear system of $N+1$ equations with $(N+13)$ unknowns $\left\{u_{i}\right\}$ :

$$
A_{1} U=F(u),
$$


where $A_{1}$ is banded matrix of order $(N+1) \times(N+13), U$ is the unknown vector of order $N+13$, and $F(u)$ is the vector of order $N+1$ that depends on $u$. The matrix $A$ and vectors $U$ and $F(u)$ are given explicitly by

$$
A_{1}=(-1)\left(g_{p q}^{\prime \prime \prime}(q-p-6)\right)_{(N+1) \times(N+13)},
$$

where $p$ and $q$ represent the row and column, respectively; that is, $p=1,2,3, \ldots, N+1$ and $q=1,2,3, \ldots, N+13$,

$$
\begin{aligned}
& F(u)=\left(h^{3} f\left(x_{0}, U\left(x_{0}\right), U^{\prime}\left(x_{0}\right)\right), \ldots,\right. \\
& \left.h^{3} f\left(x_{N}, U\left(x_{N}\right), U^{\prime}\left(x_{N}\right)\right)\right)^{T}, \\
& U=\left(u_{-6}, u_{-5}, z_{-4}, \ldots, u_{N+4}, u_{N+5}, u_{N+6}\right)^{T}, \\
& U^{\prime}\left(x_{j}\right)=\sum_{i=-6}^{N+6} u_{j} g^{\prime}\left(\frac{x_{j}-x_{i}}{h}\right) .
\end{aligned}
$$

$g^{\prime}(i)$ is defined in (13) and $g(i)=g_{i}$. System (32) is unstable and we need to make it stable to get unique solution. The detail for the stable system of nonlinear equations is given in next section.

4.3. Stable Nonlinear System. For unique solution of nonlinear systems (32), we need twelve more conditions. Three conditions can be attained from given boundary conditions for nonlinear systems of equations and remaining nine conditions are attained by setting some extrapolation method. The details of the given boundary conditions and extrapolation method are given below.

4.3.1. Approximated Boundary Condition. The given boundary conditions are

$$
\begin{gathered}
U(0)=\alpha_{1}, \\
U^{\prime}(0)=\alpha_{2}, \\
U(N)=\alpha_{3} .
\end{gathered}
$$

We see that first derivative is involved in the given boundary conditions, since approximation order of interpolating scheme (7) is eight, so we approximate derivative boundary conditions at end point with approximation order eight. The approximation of derivative conditions at end point is defined as

$$
\begin{aligned}
& U^{\prime}(0)=\left(\frac{N}{840}\right)\left\{-2283 u_{0}+6720 u_{1}-11760 u_{2}\right. \\
& +15680 u_{3}-14700 u_{4}+9408 u_{5}-3920 u_{6}+960 u_{7} \\
& \left.-105 u_{8}\right\}+O\left(h^{8}\right)
\end{aligned}
$$

4.3.2. Imposed Boundary Conditions. Remaining nine conditions for the nonlinear systems (32) to get stable systems for the solution of (1) are obtained by setting the following extrapolation method.
We define five conditions at left end points and four conditions at the right end points. Since subdivision scheme reproduces seven-degree polynomials, so we define boundary conditions of order eight for solution of (32). For simplicity only the left end points $u_{-5}, u_{-4}, u_{-3}, u_{-2}, u_{-1}$ are discussed and the values of right end points $u_{N+2}, u_{N+3}, u_{N+4}, u_{N+5}$ can be treated similarly.

The values $u_{-5}, u_{-4}, u_{-3}, u_{-2}, u_{-1}$ can be determined by the septic polynomial $R(x)$ interpolating $\left(x_{i}, u_{i}\right), 0 \leq i \leq 5$. Precisely, we have

$$
u_{-i}=R\left(-x_{i}\right), \quad i=1,2,3,4,5,
$$

where

$$
R\left(x_{i}\right)=\sum_{r=1}^{8}\left(\begin{array}{l}
8 \\
r
\end{array}\right)(-1)^{r+1} U\left(x_{i-r}\right) .
$$

Since by (16), $U\left(x_{i}\right)=u_{i}$ for $i=1,2,3,4,5$ then by replacing $x_{i}$ by $-x_{i}$, we have

$$
R\left(-x_{i}\right)=\sum_{r=1}^{8}\left(\begin{array}{l}
8 \\
r
\end{array}\right)(-1)^{r+1} u_{-i+r} .
$$

Hence, the following boundary conditions can be employed at the left end:

$$
\sum_{r=0}^{8}\left(\begin{array}{l}
8 \\
r
\end{array}\right)(-1)^{r} u_{-i+r}=0, \quad i=5,4,3,2,1 .
$$

Similarly for the right end, we can define $u_{i}=R\left(-x_{i}\right), i=$ $N+2, N+3, N+4, N+5$, and

$$
R\left(x_{i}\right)=\sum_{r=0}^{8}\left(\begin{array}{l}
8 \\
r
\end{array}\right)(-1)^{r+1} u_{i-r} .
$$

So we have the following boundary conditions at the right end:

$$
\begin{aligned}
\sum_{r=0}^{8}\left(\begin{array}{l}
8 \\
r
\end{array}\right)(-1)^{r} u_{i-r}= & \\
& \quad i=N+2, N+3, N+4, N+5 .
\end{aligned}
$$

Finally, we get the following new system of $(N+13)$ linear equations with $(N+13)$ unknowns $\left\{u_{i}\right\}$, in which $N+1$ equations are obtained from (22), three equations from boundary conditions (36), and nine from boundary conditions (41) and (43).

Hence, the stable nonlinear system of equations is defined as

$$
A U=G(u)
$$

where the matrix $A$ is given by

$$
A=\left(A_{0}^{T}, A_{1}^{T}, A_{2}^{T}\right)^{T},
$$

and the matrix $A_{1}$ is defined in (33). The matrix $\left(A_{0}\right)_{7 \times(N+13)}$ is constructed by taking first five rows from (41), sixth row from (37), and the last row $U(0)$ from (36). Hence, 
$A_{0}$

$$
=\left(\begin{array}{cccccccccccccccccccccc}
0 & 1 & -8 & 28 & -56 & 70 & -56 & 28 & -8 & 1 & 0 & 0 & 0 & 0 & 0 & 0 & \cdots & 0 & 0 \\
0 & 0 & 1 & -8 & 28 & -56 & 70 & -56 & 28 & -8 & 1 & 0 & 0 & 0 & 0 & 0 & \cdots & 0 & 0 \\
0 & 0 & 0 & 1 & -8 & 28 & -56 & 70 & -56 & 28 & -8 & 1 & 0 & 0 & 0 & 0 & \cdots & 0 & 0 \\
0 & 0 & 0 & 0 & 1 & -8 & 28 & -56 & 70 & -56 & 28 & -8 & 1 & 0 & 0 & 0 & \cdots & 0 & 0 \\
0 & 0 & 0 & 0 & 0 & 1 & -8 & 28 & -56 & 70 & -56 & 28 & -8 & 1 & 0 & 0 & \cdots & 0 & 0 \\
0 & 0 & 0 & 0 & 0 & 0 & -\frac{2283 N}{840} & \frac{6720 N}{840} & -\frac{11760 N}{840} & \frac{15680 N}{840} & -\frac{14700 N}{840} & \frac{9408 N}{840} & -\frac{3920 N}{840} & \frac{960 N}{840} & -\frac{105 N}{840} & 0 & \cdots & 0 & 0 \\
0 & 0 & 0 & 0 & 0 & 0 & 1 & 0 & 0 & 0 & 0 & 0 & 0 & 0 & 0 & 0 & \cdots & 0 & 0
\end{array}\right) .
$$

The matrix $\left(A_{2}\right)_{6 \times(N+13)}$ is constructed by taking first row $U(N)$ from (36) and last five rows are obtained from (43).

Hence,

$$
A_{2}=\left(\begin{array}{ccccccccccccccccc}
0 & 0 & \cdots & 0 & 0 & 0 & 0 & 0 & 0 & 0 & 1 & 0 & 0 & 0 & 0 & 0 & 0 \\
0 & 0 & \cdots & 1 & -8 & 28 & -56 & 70 & -56 & 28 & -8 & 1 & 0 & 0 & 0 & 0 & 0 \\
0 & 0 & \cdots & 0 & 1 & -8 & 28 & -56 & 70 & -56 & 28 & -8 & 1 & 0 & 0 & 0 & 0 \\
0 & 0 & \cdots & 0 & 0 & 1 & -8 & 28 & -56 & 70 & -56 & 28 & -8 & 1 & 0 & 0 & 0 \\
0 & 0 & \cdots & 0 & 0 & 0 & 1 & -8 & 28 & -56 & 70 & -56 & 28 & -8 & 1 & 0 & 0
\end{array}\right) .
$$

The column vector $U$ is defined in (35) and $G$ is defined as

$$
\begin{aligned}
& G(u) \\
& \quad=\left(0,0,0,0,0, U^{\prime}(0), U(0), F^{T}(u), U(1), 0,0,0,0\right)^{T},
\end{aligned}
$$

where $F(u)$ is defined by $(34)$.

4.3.3. Nonsingularity of a Matrix. The nonsingularity of coefficient matrix $A$, which is defined in (45), can be checked by different methods.

Since the determinant of matrix $A$ is nonzero for $N \leq$ 2000 then the nonlinear system of equations give solution for $N \leq 2000$.

It is also observed that all the eigenvalues are nonzero for $N \leq 2000$. Hence, by [14] matrix $A$ is nonsingular. For large $N>2000$ the matrix may or may not be nonsingular.

The coefficient matrix $A$ is neither symmetric nor diagonally dominant. Though it can be proved that $A$ is nonsingular/invertible, the matrix is almost symmetric except the first and last few rows and columns due to its boundary treatment for large value of $N$. Therefore, we first consider the symmetric part of it, that is, the square band matrix $B$ of order $N+1$ defined as

$$
\begin{aligned}
& (-1) \times B \\
& =\left(\begin{array}{ccccccccc}
g_{1}^{\prime \prime \prime} & g_{2}^{\prime \prime \prime} & g_{3}^{\prime \prime \prime} & g_{4}^{\prime \prime \prime} & \ldots & \ldots & 0 & 0 & 0 \\
g_{0}^{\prime \prime \prime} & g_{1}^{\prime \prime \prime} & g_{2}^{\prime \prime \prime} & g_{3}^{\prime \prime \prime} & \ldots & \ldots & 0 & 0 & 0 \\
g_{-1}^{\prime \prime \prime} & g_{0}^{\prime \prime \prime} & g_{1}^{\prime \prime \prime} & g_{2}^{\prime \prime \prime} & \ldots & \ldots & 0 & 0 & 0 \\
g_{-2}^{\prime \prime \prime} & g_{-1}^{\prime \prime \prime} & g_{0}^{\prime \prime \prime} & g_{1}^{\prime \prime \prime} & \ldots & \ldots & 0 & 0 & 0 \\
g_{-3}^{\prime \prime \prime} & g_{-2}^{\prime \prime \prime} & g_{-1}^{\prime \prime \prime} & g_{0}^{\prime \prime \prime} & \ldots & \ldots & 0 & 0 & 0 \\
\ldots & \ldots & \ldots & \ldots & \ldots & \ldots & \ldots & \ldots & \ldots \\
0 & 0 & 0 & 0 & \cdots & \cdots & g_{2}^{\prime \prime \prime} & g_{2}^{\prime \prime \prime} & g_{3}^{\prime \prime \prime} \\
0 & 0 & 0 & 0 & \cdots & \cdots & g_{0}^{\prime \prime \prime} & g_{1}^{\prime \prime \prime} & g_{2}^{\prime \prime \prime} \\
0 & 0 & 0 & 0 & \cdots & \cdots & g_{-1}^{\prime \prime \prime} & g_{0}^{\prime \prime \prime} & g_{1}^{\prime \prime \prime}
\end{array}\right) .
\end{aligned}
$$

Kılıç and Stanica [15] presented a method to find the inverse of banded matrix of order $n$ by using the LU factorization of the banded matrix. As $B$ is a band matrix of order $(N+1)$ so by LU factorization method its inverse exists. 
4.4. Iterative Algorithm and Its Convergence. In this section, we propose an iterative algorithm and discuss its convergence.

4.4.1. Iterative Algorithm Based on Basis Function. The iterative algorithm is based on basis function of the subdivision scheme (7) as defined in the following three steps.

First Step (initial approximation). Initial approximation is important because numerical solution depends on the initial approximation. We define the process for finding the initial approximation as follows.

Let initial approximate solution $U^{0}$ be the solution of the following linear system:

$$
A U^{0}=G^{0}
$$

where

$$
\begin{aligned}
G^{0} & =\left(0,0,0,0,0, y^{\prime}(a), y(a), p_{0}, p_{1}, p_{2}, \ldots, p_{N}, y(b),\right. \\
& 0,0,0,0)^{T}, \\
p_{i} & =h^{3} p\left(x_{i}, m_{i}, S\right), \quad i=0,1,2, \ldots, N, a \leq x \leq b, \\
m_{i} & =y(a)+i h\left(\frac{y(b)-y(a)}{b-a}\right), \\
S & =y(b)-y(a) .
\end{aligned}
$$

$G^{0}$ is the initial linear approximation of the nonlinear vector $G(u)$. By solving the linear system of (50) we get initial approximate solution.

Second Step (numerical solution). The numerical solutions $U^{*}$ of the nonlinear system are obtained by using simple iterative scheme:

$$
A U^{(m+1)}=G\left(U^{m}\right), \quad m=0,1,2,3, \ldots
$$

Third Step (stopping condition). The above iterative processes will terminate when the following condition is satisfied

$$
\left\|U^{m}-U^{m-1}\right\| \leq \text { tol }
$$

where tol is supposed value; that is, tol $=10^{-6}$. The convergence of the above iterative algorithm is guaranteed by the following propositions. The solutions of linear system of (50) and (52) are obtained by Gaussian eliminations method.

Proposition 6. The successive solutions $\left\{U^{m}\right\}$ for the nonlinear system (44) generated by the iterative algorithm (52) linearly converge to the solution $U^{*}$ provided that $M_{0}$ and $M_{1}$ are Lipschitz constants and step size $h$ is small. That is,

$$
\left\|A^{-1}\right\|\left(M_{0} h^{3}+\frac{867307}{212370} M_{1} h^{2}\right) \leq 1 .
$$

Proof. Let $U^{*}$ and $U^{(m)}$ be the solutions of the nonlinear system (44) then by definition, for small $h$, we have

$$
\begin{gathered}
A U^{*}=G\left(U^{*}\right), \\
A U^{(m+1)}=G\left(U^{(m)}\right) .
\end{gathered}
$$

Let the error vector be defined as $e^{(m)}=U^{m}-U^{*}$ at $m$ th iteration which satisfies

$$
\begin{aligned}
A U^{(m+1)}-A U^{*} & =G\left(U^{(m)}\right)-G\left(U^{*}\right), \\
G\left(U^{(m+1)}-U^{*}\right) & =G\left(U^{(m)}\right)-G\left(U^{*}\right), \\
A e^{(m+1)} & =G\left(U^{m}\right)-G\left(U^{*}\right) .
\end{aligned}
$$

For $i=0,1,2, \ldots, N$,

$$
D_{3} e_{i}^{(m+1)}=\left(F\left(U^{(m)}\right)-F\left(U^{*}\right)\right)_{i},
$$

by using the mean value theorem, which is stated as "if a function $f(x, y, z)$ is continuously differentiable in an open set of $\mathbb{R}^{3}$ containing points $\left(x_{1}, y_{1}, z_{1}\right)$ and $\left(x_{2}, y_{2}, z_{2}\right)$ and the line segment connecting them, then an equation

$$
\begin{aligned}
f\left(x_{2}, y_{2}, z_{2}\right)-f\left(x_{1}, y_{1}, z_{1}\right) & \\
= & f_{x}^{\prime}(r, s, t)\left(x_{2}-x_{1}\right)+f_{y}^{\prime}(r, s, t)\left(y_{2}-y_{1}\right) \\
& \quad+f_{z}^{\prime}(r, s, t)\left(z_{2}-z_{1}\right)
\end{aligned}
$$

is valid for the interior point $(a, b, c)$ of the segment." We have

$$
D_{3} e_{i}^{(m+1)}=f\left(x_{i}, U_{i}^{(m)}, U^{\prime(m)}\right)-f\left(x_{i}, U_{i}^{(*)}, U^{\prime(*)}\right) .
$$

The above equation can be written as (by using mean value theorem)

$$
\begin{aligned}
D_{3} e_{i}^{(m+1)}= & f_{x}^{*}\left(x_{i}-x_{i}\right)+f_{y}^{*}\left(U_{i}^{(m)}-U_{i}^{(*)}\right) \\
& +f_{y^{\prime}}^{*}\left(U^{\prime(m)}-U^{\prime(*)}\right),
\end{aligned}
$$

and by using the definition of error vector, we have

$$
\begin{aligned}
& D_{3} e_{i}^{(m+1)}=f_{y}^{*} e_{i}^{(m)}+f_{y^{\prime}}^{*} e_{i}^{\prime(m)}, \\
& D_{3} e_{i}^{(m+1)}=f_{y}^{*} e_{i}^{(m)}+f_{y^{\prime}}^{*} D_{1} e_{i}^{(m)},
\end{aligned}
$$

where $D_{3}$ and $D_{1}$ are the derivative difference operators defined as

$$
\begin{aligned}
& D_{1} f_{i}=\frac{1}{2973180 h}\left[-5\left(f_{i+6}-f_{i-6}\right)\right. \\
& \quad+1024\left(f_{i+5}-f_{i-5}\right)+13225\left(f_{i+4}-f_{i-4}\right) \\
& \quad-199680\left(f_{i+3}-f_{i-3}\right)+1141695\left(f_{i+2}-f_{i-2}\right) \\
& \left.\quad-4715520\left(f_{i+1}-f_{i-1}\right)\right] \\
& D_{3} f_{i}=\frac{1}{1879920 h^{3}}\left[-225\left(f_{i+6}-f_{i-6}\right)\right. \\
& \quad+11520\left(f_{i+5}-f_{i-5}\right)-10952\left(f_{i+4}-f_{i-4}\right) \\
& \quad-476928\left(f_{i+3}-f_{i-3}\right)+3047987\left(f_{i+2}-f_{i-2}\right) \\
& \left.\quad-4677632\left(f_{i+1}-f_{i-1}\right)\right] .
\end{aligned}
$$


This implies

$$
D_{3} e_{i}^{(m+1)}=h^{3} f_{y}^{*} e_{i}^{(m)}+h^{2} f_{y^{\prime}}^{*} D_{1} e_{i}^{(m)} .
$$

Since $e_{i}=e_{N-i}=0, i=0,-1,-2, \ldots,-6$, therefore, we have

$$
A e_{i}^{(m+1)}=h^{3} f_{y}^{*} e_{i}^{(m)}+h^{2} f_{y^{\prime}}^{*} D_{1} e_{i}^{(m)}
$$

This can be written as

$$
e_{i}^{(m+1)}=A^{-1}\left(h^{3} f_{y}^{*} e_{i}^{(m)}+h^{2} f_{y^{\prime}}^{*} D_{1} e_{i}^{(m)}\right) .
$$

By taking norm on both sides, we get

$$
\left\|e_{i}^{(m+1)}\right\|=\left\|A^{-1}\right\|\left\|h^{3} f_{y}^{*} e_{i}^{(m)}+h^{2} f_{y^{\prime}}^{*} D_{1} e_{i}^{(m)}\right\| .
$$

By using the definition of Lipschitz condition, we get

$$
\left\|e_{i}^{(m+1)}\right\| \leq\left\|A^{-1}\right\|\left(h^{3} M_{0}\left\|e_{i}^{(m)}\right\|+h^{2} M_{1}\left\|D_{1}\right\|\left\|e_{i}^{(m)}\right\|\right) .
$$

This implies

$$
\frac{\left\|e_{i}^{(m+1)}\right\|}{\left\|e_{i}^{(m)}\right\|} \leq\left\|A^{-1}\right\|\left(h^{3} M_{0}+h^{2} M_{1}\left\|D_{1}\right\|\right),
$$

which is equivalent to

$$
\frac{\left\|e_{i}^{(m+1)}\right\|}{\left\|e_{i}^{(m)}\right\|} \approx h^{2} M_{1}\left\|A^{-1}\right\|\left\|D_{1}\right\| .
$$

The results follow immediately from this inequality and the following fact:

$$
\left\|D_{1}\right\|=\frac{867307}{212370}
$$

A simple approximation of condition by omitting the cubic term is

$$
h \leq\left(\frac{212370}{867307} M_{1}^{-1}\left\|A^{-1}\right\|^{-1}\right)^{1 / 2} .
$$

This completes the proof.

Proposition 7. If $f$ satisfies the Lipschitz condition (3) and Lipschitz constants $M_{0}, M_{1}$, and $M_{2}$ and mesh size $h$ are small enough then nonlinear system (32) has a unique solution $U^{*}$. A sufficient condition for the existence of a solution is given by (54).

Proof. From the proof of previous proposition, we observe that if (54) holds, then an inequality similar to that of (67) holds, which implies that the sequence $\left\{U^{m}\right\}$ is contracting and hence converges. The limit $U^{*}$ of (52) also satisfies (44) due to the continuity of the right hand side function $f\left(x, y, y^{\prime}, y^{\prime \prime}\right)$.

Remark 8. The numerical complexity for the solution of the linear system (52), where the matrix $A$ is almost band matrix with half band 7, using Gaussian elimination method is about $49(N+13)$ multiplications. The number of complexities depends upon the efficient boundary treatment. If more efficient boundary treatment is constructed then number of complexities will be reduced.

\section{Error Analysis}

From the approximation properties of the basis function $g(x)$, it is shown that the collocation method (16) with nonic precision treatments at end points has at least the power of approximation $O\left(h^{3}\right)$. Here we present our main results for error estimation. Proof of these results is similar to the proof of Proposition in [9].

Proposition 9. Suppose the exact solution $y(x) \in C^{3}[0,1]$ and $\left\{u_{i}\right\}$ are obtained by (67) then absolute error by interpolating collocation algorithm is

$$
\begin{array}{r}
\|\operatorname{err}(x)\|_{\infty}=\left\|U^{(l)}(x)-y^{(l)}(x)\right\|_{\infty}=O\left(h^{3-l}\right), \\
\quad l=0,1,2,3,
\end{array}
$$

wherel denotes the order of derivative.

Proof. Since the order of approximation of subdivision scheme (2) is ten so by direct calculation (third left eigenvector), we can find derivative of smooth function $y(x)$ as

$$
\begin{aligned}
y^{\prime \prime \prime} & \left(x_{j}\right) \\
& =\frac{1}{1879920 h^{3}}\left[-225\left\{y\left(x_{j}+6 h\right)-y\left(x_{j}-6 h\right)\right\}\right. \\
& +11520\left\{y\left(x_{j}+5 h\right)-y\left(x_{j}-5 h\right)\right\} \\
& -10952\left\{y\left(x_{j}+4 h\right)+y\left(x_{j}-4 h\right)\right\} \\
& -476928\left\{y\left(x_{j}+3 h\right)+y\left(x_{j}-3 h\right)\right\} \\
& +3047987\left\{y\left(x_{j}+2 h\right)-y\left(x_{j}-2 h\right)\right\} \\
& \left.-4677632\left\{y\left(x_{j}+h\right)-y\left(x_{j}-h\right)\right\}\right]+O\left(h^{8}\right) .
\end{aligned}
$$

This can be written as

$$
\begin{aligned}
& y^{\prime \prime \prime}\left(x_{j}\right)=\frac{1}{1879920 h^{3}}\left[-225\left(y_{j+6}-y_{j-6}\right)\right. \\
& \quad+11520\left(y_{j+5}-y_{j-5}\right)-10952\left(y_{j+4}-y_{j-4}\right) \\
& \quad-476928\left(y_{j+3}-y_{j-3}\right)+3047987\left(y_{j+2}-y_{j-2}\right) \\
& \left.\quad-4677632\left(y_{j+1}-y_{j-1}\right)\right]+O\left(h^{8}\right) .
\end{aligned}
$$

Similarly, we have

$$
\begin{aligned}
& U^{\prime \prime \prime}\left(x_{j}\right)=\frac{1}{1879920 h^{3}}\left[-225\left(u_{j+6}-u_{j-6}\right)\right. \\
& \quad+11520\left(u_{j+5}-u_{j-5}\right)-10952\left(u_{j+4}-u_{j-4}\right) \\
& \quad-476928\left(u_{j+3}-u_{j-3}\right)+3047987\left(u_{j+2}-u_{j-2}\right) \\
& \left.\quad-4677632\left(u_{j+1}-u_{j-1}\right)\right]+O\left(h^{8}\right) .
\end{aligned}
$$


If we define error function $e(x)=U(x)-y(x)$ and error vectors at the nodes by

$$
e\left(x_{j}\right)=U\left(x_{j}\right)-y\left(x_{j}+j h\right), \quad-6 \leq j \leq N+6,
$$

or equivalently $e_{j}=Z_{j}-y_{j},-6 \leq j \leq N+6$, then this implies

$$
\begin{aligned}
e_{j}^{\prime} & =U_{j}^{\prime}-y_{j}^{\prime}, \\
e_{j}^{\prime \prime} & =U_{j}^{\prime \prime}-y_{j}^{\prime \prime}, \\
e_{j}^{\prime \prime \prime} & =U_{j}^{\prime \prime \prime}-y_{j}^{\prime \prime \prime} .
\end{aligned}
$$

By subtracting (75) from (74), we get

$$
\begin{aligned}
y_{j}^{\prime \prime \prime} & -U_{j}^{\prime \prime \prime}=\frac{1}{1879920 h^{3}}\left[-225\left\{\left(y_{j+6}-y_{j-6}\right)\right.\right. \\
& \left.-\left(u_{j+6}-u_{j-6}\right)\right\}+11520\left\{\left(y_{j+5}-y_{j-5}\right)\right. \\
& \left.-\left(u_{j+5}-u_{j-5}\right)\right\}-10952\left\{\left(y_{j+4}-y_{j-4}\right)\right. \\
& \left.-\left(u_{j+4}-u_{j-4}\right)\right\}-476928\left\{\left(y_{j+3}-y_{j-3}\right)\right. \\
& \left.-\left(u_{j+3}-u_{j-3}\right)\right\}+3047987\left\{\left(y_{j+2}-y_{j-2}\right)\right. \\
& \left.-\left(u_{j+2}-u_{j-2}\right)\right\}-4677632\left\{\left(y_{j+1}-y_{j-1}\right)\right. \\
& \left.\left.-\left(u_{j+1}-u_{j-1}\right)\right\}\right]+O\left(h^{8}\right) .
\end{aligned}
$$

This implies

$$
\begin{aligned}
e_{j}^{\prime \prime \prime} & =\frac{1}{1879920 h^{3}}\left[-225\left(e_{j+6}-e_{j-6}\right)\right. \\
& +11520\left(e_{j+5}-e_{j-5}\right)-10952\left(e_{j+4}-e_{j-4}\right) \\
& -476928\left(e_{j+3}-e_{j-3}\right)+3047987\left(e_{j+2}-e_{j-2}\right) \\
& \left.-4677632\left(e_{j+1}-e_{j-1}\right)\right]+O\left(h^{8}\right) .
\end{aligned}
$$

From (1), (16), and (79) and by assuming the eighth order boundary treatments at the end points, we have

$$
\begin{aligned}
e_{j}^{\prime \prime \prime}= & a_{j} e_{j}+b_{j} e_{j}^{\prime}, \quad 0 \leq i \leq N, \\
e_{j} & = \begin{cases}\max _{0 \leq k \leq 6}\left\{\left|e_{k}\right|\right\} O\left(h^{8}\right), & -6 \leq j \leq 0 \\
\max _{N-6 \leq k \leq N}\left\{\left|e_{k}\right|\right\} O\left(h^{8}\right), & N \leq j \leq N+6,\end{cases}
\end{aligned}
$$

where $j=0,1, \ldots, N$,

$$
\begin{aligned}
a_{j} & =f_{y}\left(t_{j}, y_{j}^{*}, y_{j}^{\prime *}\right), \\
b_{j} & =f_{y^{\prime}}\left(t_{j}, y_{j}^{*}, y_{j}^{\prime *}\right), \\
y_{j}^{*} & =y_{j}+\theta_{j} e_{j}, \\
y_{j}^{\prime *} & =y_{j}^{\prime}+\theta_{j} e_{j}^{\prime},
\end{aligned}
$$

Using the results (79) and

$$
\begin{aligned}
& D_{1} U_{i}=\frac{1}{2973180 h}\left[-5\left(u_{i+6}-u_{i-6}\right)\right. \\
& \quad+1024\left(u_{i+5}-u_{i-5}\right)+13225\left(u_{i+4}-u_{i-4}\right) \\
& \quad-199680\left(u_{i+3}-u_{i-3}\right)+1141695\left(u_{i+2}-u_{i-2}\right) \\
& \left.\quad-4715520\left(u_{i+1}-u_{i-1}\right)\right]
\end{aligned}
$$

it can be concluded that relation (80) is equivalent to

$$
\left(A+O\left(h^{6}\right)-O\left(h^{3}\right)-D_{1} O(h)\right) E=O\left(h^{8}\right)\|E\|,
$$

where $E=\left(e_{-6}, e_{-5}, \ldots, e_{5}, e_{6}\right)$.

Hence, for small $h$, the coefficient matrix $A+O\left(h^{2}\right)$ will be invertible; thus using the standard result from algebra and effect of $\left\|A^{-1}\right\|$, we have the following estimate:

$$
\|E\| \leq \frac{\left\|A^{-1}\right\|}{1-O\left(h^{2}\right)} O\left(h^{8}\right)=O\left(h^{3}\right) .
$$

This completes the result.

\section{Examples, Comparison, and Conclusion}

In this section, we use subdivision based collocation algorithm to find the solution of some nonlinear third-order boundary value problems. We present numerical results in table format along with their graphical representations. We also give comparison of the results obtained by our algorithm and the results computed by existing algorithms. We end this section with precise conclusion.

6.1. Numerical Examples. We find the approximate solutions of the following nonlinear problems to check the accuracy and convergence of subdivision based iterative collocation algorithm.

Example 1. The nonlinear boundary value problem is

$$
y^{\prime \prime \prime}=-2 e^{-3 y}+4(1+x)^{-3},
$$

with boundary conditions

$$
\begin{aligned}
y(0) & =0, \\
y^{\prime}(0) & =1, \\
y(1) & =\ln (2) .
\end{aligned}
$$

Example 2. The nonlinear boundary value problem is

$$
y^{\prime \prime \prime}(x)=e^{-x} y^{2}(x)
$$

subject to the boundary conditions:

$$
\begin{gathered}
y(0)=1, \\
y^{\prime}(0)=1, \\
y(1)=e .
\end{gathered}
$$


TABLE 1: Numerical results of Example 1: $h=10^{-1}$.

\begin{tabular}{lcccc}
\hline$x_{i}$ & Analytic solution $Y_{i}$ & Approximate solution $Z_{i}$ & Error by proposed method & Error by method [5] \\
\hline 0.0 & 0 & 0 & 0 & 0 \\
0.1 & 0.0953101798 & 0.0957100706 & 0.0003998908 & 0.009 \\
0.2 & 0.1823215568 & 0.1836519852 & 0.0013304284 & 0.013 \\
0.3 & 0.2623642645 & 0.2648256813 & 0.0024614168 & 0.031 \\
0.4 & 0.3364722366 & 0.3400108156 & 0.0035385790 & 0.045 \\
0.5 & 0.4054651081 & 0.4098275640 & 0.0043624559 & 0.054 \\
0.6 & 0.4700036292 & 0.4747771017 & 0.0047734725 & 0.058 \\
0.7 & 0.5306282511 & 0.5352702927 & 0.0046420416 & 0.058 \\
0.8 & 0.5877866649 & 0.5916474874 & 0.0038608225 & 0.053 \\
0.9 & 0.6418538862 & 0.6441934825 & 0.0023395963 & 0.044 \\
1.0 & 0.6931471806 & 0.6931471806 & 0 & 0.000 \\
\hline
\end{tabular}

Example 3. The nonlinear boundary value problem is

$$
y^{\prime \prime \prime}(x)=-e^{x} y^{2}(x)
$$

subject to the boundary conditions:

$$
\begin{gathered}
y(0)=1, \\
y^{\prime}(0)=-1, \\
y(1)=\frac{1}{e} .
\end{gathered}
$$

The exact solutions of problems (85), (87), and (89) are $y=$ $\ln (1+x), y=e^{x}$, and $y=e^{-x}$, respectively.

Example 4. We consider the third-order ordinary differential equation:

$$
y^{\prime \prime \prime}=y^{-k}, \quad y \geqslant 0
$$

where $k$ is constant. The initial conditions imposed by Tanner [16] are

$$
\begin{gathered}
y(0)=1, \\
y^{\prime}(0)=0 .
\end{gathered}
$$

The problem is closed by the boundary condition:

$$
y(r)=0
$$

and the problem becomes singular at $y=0$. The boundary condition is imposed [17] as

$$
y(r)=\epsilon,
$$

where $r$ is a constant satisfying $r>0$. The analytical solution of (91) by [17]

$$
y(x)=\frac{1}{6}\left(6-7 x^{2}+6 \epsilon x^{2}+x^{3}\right) .
$$

Case 1 (see [17]). For $k=0$ problem (91) takes the form

$$
y^{\prime \prime \prime}=y^{0}=1 \text {. }
$$

We solve (96) along with conditions (92) and (94) by letting $r=1$; then $\epsilon=11 / 12$ and we obtain the results which also support our algorithm. That is, the numerical results have the order of approximation $O\left(h^{3}\right)$. The numerical results are tabulated in Table 4 and graphical representation of these results is shown in Figure 4 . These results are obtained after first iteration level. The maximum absolute error is $6.1250 \times$ $10^{-3}$.

Case 2 (see [17]). For $k=1 / 2$ problem (91) takes the form

$$
y^{\prime \prime \prime}=y^{-1 / 2}
$$

with the boundary conditions $y(0)=1, y^{\prime}(0)=0$, and $y(r)=\epsilon$. The numerical solution of (97) is obtained by using the proposed numerical algorithm. The solution after third iteration level is presented in Table 5 and their graphical representation is presented in Figure 5. The maximum absolute error for this problem is $6.4004 \times 10^{-3}$.

Case 3 (see $[17,18]$ ). In this case, we numerically solve problem (91) for $k=2$; that is,

$$
y^{\prime \prime \prime}=y^{-2}
$$

together with the boundary conditions $y(0)=1, y^{\prime}(0)=0$, and $y(r)=\epsilon$. Its exact solution is given in (95). The numerical solution of (98) with given and imposed condition at node points is tabulated in Table 6 and graphical representation is given in Figure 6. The maximum absolute error for this problem is $4.93276 \times 10^{-3}$.

6.2. Comparison and Discussion. For Examples 1, 2, and 3, we use the iterative collocation algorithm described in Section 4, for $h=10^{-1}, 20^{-1}, 50^{-1}$ (i.e., for $N=10,20,50$ ) and tol $=10^{-6}$ along with eighth-order boundary treatment at end points, to get solutions of nonlinear boundary value problems. The numerical results are obtained after third iteration with condition (53).

(i) The numerical solutions of problems (85), (87), and (89) are presented in Tables 1, 2, and 3, respectively. 
TABLE 2: Numerical results of Example 2: $h=10^{-1}$.

\begin{tabular}{cccc}
\hline$x_{i}$ & $\begin{array}{c}\text { Analytic solution } \\
Y_{i}\end{array}$ & $\begin{array}{c}\text { Approximate } \\
\text { solution } Z_{i}\end{array}$ & $\begin{array}{c}\text { Error by } \\
\text { proposed method }\end{array}$ \\
\hline 0.0 & 1 & 1 & 0 \\
0.1 & 1.105170918 & 1.1056664532 & 0.000495535 \\
0.2 & 1.221402758 & 1.2232054699 & 0.001802712 \\
0.3 & 1.349858808 & 1.3534912400 & 0.003632432 \\
0.4 & 1.491824698 & 1.4974920669 & 0.005667369 \\
0.5 & 1.648721271 & 1.6562805667 & 0.007559296 \\
0.6 & 1.822118800 & 1.8310443828 & 0.008925583 \\
0.7 & 2.013752707 & 2.0230974700 & 0.009344763 \\
0.8 & 2.225540928 & 2.2338920118 & 0.008351084 \\
0.9 & 2.459603111 & 2.4650310392 & 0.005427928 \\
1.0 & 2.718281828 & 2.7182818285 & 0 \\
\hline
\end{tabular}

TABLE 3: Numerical results of Example 3: $h=10^{-1}$.

\begin{tabular}{cccc}
\hline$x_{i}$ & $\begin{array}{c}\text { Analytic solution } \\
Y_{i}\end{array}$ & $\begin{array}{c}\text { Approximate } \\
\text { solution } Z_{i}\end{array}$ & $\begin{array}{c}\text { Error by } \\
\text { proposed method }\end{array}$ \\
\hline 0.0 & 1 & 1 & 0 \\
0.1 & 0.9048374180 & 0.9045439989 & 0.0002934191 \\
0.2 & 0.8187307531 & 0.8177120092 & 0.0010187439 \\
0.3 & 0.7408182207 & 0.7388586762 & 0.0019595445 \\
0.4 & 0.6703200460 & 0.6674013997 & 0.0029186463 \\
0.5 & 0.6065306597 & 0.6028146540 & 0.0037160057 \\
0.6 & 0.5488116363 & 0.5446245817 & 0.0041870544 \\
0.7 & 0.4965853038 & 0.4924038346 & 0.0041814692 \\
0.8 & 0.4493289641 & 0.4457666384 & 0.0035623257 \\
0.9 & 0.4065696597 & 0.4043640577 & 0.0022056020 \\
1.0 & 0.3678794412 & 0.3678794412 & 0 \\
\hline
\end{tabular}

TABLE 4: Numerical results of Example 4: $k=0$ and $h=10^{-1}$.

\begin{tabular}{cccc}
\hline$x_{i}$ & $\begin{array}{c}\text { Analytic solution } \\
Y_{i}\end{array}$ & $\begin{array}{c}\text { Approximate } \\
\text { solution } Z_{i}\end{array}$ & $\begin{array}{c}\text { Error by } \\
\text { proposed method }\end{array}$ \\
\hline 0.0 & 1 & 1 & 0 \\
0.1 & 0.9976666667 & 0.9980416667 & 0.0003750000 \\
0.2 & 0.9913333333 & 0.9926666667 & 0.0013333334 \\
0.3 & 0.9820000000 & 0.9846250000 & 0.0026250000 \\
0.4 & 0.9706666667 & 0.9746666667 & 0.0040000000 \\
0.5 & 0.9583333333 & 0.9635416667 & 0.0052083334 \\
0.6 & 0.9460000000 & 0.9520000000 & 0.0060000000 \\
0.7 & 0.9346666667 & 0.9407916667 & 0.0061250000 \\
0.8 & 0.9253333333 & 0.9306666667 & 0.0053333334 \\
0.9 & 0.9190000000 & 0.9223750000 & 0.0033750000 \\
1.0 & 0.9166666667 & 0.9166666667 & 0 \\
\hline
\end{tabular}

(ii) Caglar et al. [5] solved problem (85) by fourth-degree B-spline algorithm. The maximum absolute errors obtained by the proposed algorithm and by [5] are $4.77 \times 10^{-3}$ and $5.80 \times 10^{-2}$, respectively. The graphical
TABle 5: Numerical results of Example 4: $k=1 / 2$ and $h=10^{-1}$.

\begin{tabular}{cccc}
\hline$x_{i}$ & $\begin{array}{c}\text { Analytic solution } \\
Y_{i}\end{array}$ & $\begin{array}{c}\text { Approximate } \\
\text { solution } Z_{i}\end{array}$ & $\begin{array}{c}\text { Error by } \\
\text { proposed method }\end{array}$ \\
\hline 0.0 & 1 & 1 & 0 \\
0.1 & 0.9976666667 & 0.9980508018 & 0.0003841351 \\
0.2 & 0.9913333333 & 0.9927028673 & 0.0013695340 \\
0.3 & 0.9820000000 & 0.9847044600 & 0.0013695340 \\
0.4 & 0.9706666667 & 0.9748013302 & 0.0041346635 \\
0.5 & 0.9583333333 & 0.9637358441 & 0.0054025108 \\
0.6 & 0.9460000000 & 0.9522463844 & 0.0062463844 \\
0.7 & 0.9346666667 & 0.9410670255 & 0.0064003588 \\
0.8 & 0.9253333333 & 0.9309274865 & 0.0055941532 \\
0.9 & 0.9190000000 & 0.9225533666 & 0.0035533666 \\
1.0 & 0.9166666667 & 0.9166666692 & 0 \\
\hline
\end{tabular}

TABLE 6: Numerical results of Example 4: $k=2$ and $h=10^{-1}$.

\begin{tabular}{cccc}
\hline$x_{i}$ & $\begin{array}{c}\text { Analytic solution } \\
Y_{i}\end{array}$ & $\begin{array}{c}\text { Approximate } \\
\text { solution } Z_{i}\end{array}$ & $\begin{array}{c}\text { Error by } \\
\text { proposed method }\end{array}$ \\
\hline 0.0 & 1 & 1 & 0 \\
0.1 & 0.9976666667 & 0.9980024045 & 0.0003357378 \\
0.2 & 0.9913333333 & 0.9925110306 & 0.0011776973 \\
0.3 & 0.9820000000 & 0.9842830603 & 0.0022830603 \\
0.4 & 0.9706666667 & 0.9740862436 & 0.0034195769 \\
0.5 & 0.9583333333 & 0.9627028681 & 0.0043695348 \\
0.6 & 0.9460000000 & 0.9509327630 & 0.0049327630 \\
0.7 & 0.9346666667 & 0.9395952385 & 0.0049285718 \\
0.8 & 0.9253333333 & 0.9295297470 & 0.0041964137 \\
0.9 & 0.9190000000 & 0.9215950588 & 0.0025950588 \\
1.0 & 0.9166666667 & 0.9166666667 & 0 \\
\hline
\end{tabular}

comparison between exact and approximate solutions is shown in Figure 1. We observe that numerical results obtained by proposed algorithm are better than the results of [5].

(iii) Hasan [3] solved problem (87) by modified Adomian decomposition method (MADM). We also solve this problem by subdivision based collocation algorithm. Here we observe that the order of approximation by proposed and MADM algorithms is the same (i.e., $\left.O\left(h^{3}\right)\right)$. The graphical comparison between exact and approximate solutions is shown in Figure 2.

(iv) The comparison between exact and approximate solutions of problem (89) is given in Figure 3.

In Example 4, we consider the problem related to thin film flows. We solve (91) by assuming different values of $k$ and we observer from the numerical results tabulated in Tables 4, 5, and 6 that accuracy of the approximate solution is $O\left(h^{3}\right)$. The numerical results are obtained after first and third iterations for $k=0$ and $k=1 / 2,1$ with condition (53), respectively.

The numerical solutions of Examples 1, 2, and 3 at different step sizes are shown in Figure 7. From this figure, we 


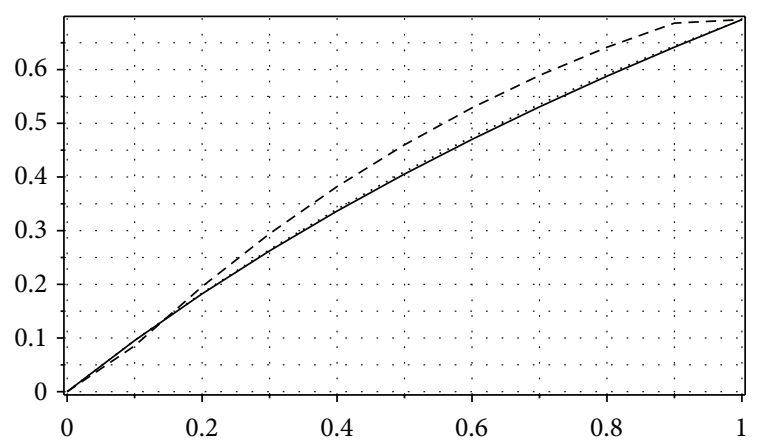

FIgURE 1: Comparison of the analytic and approximate solution of Example 1 by proposed algorithm and [5]. In this figure solid line shows exact solution, dotted lines show approximate solution by proposed algorithm, and dashed lines show the solution obtained by [5].

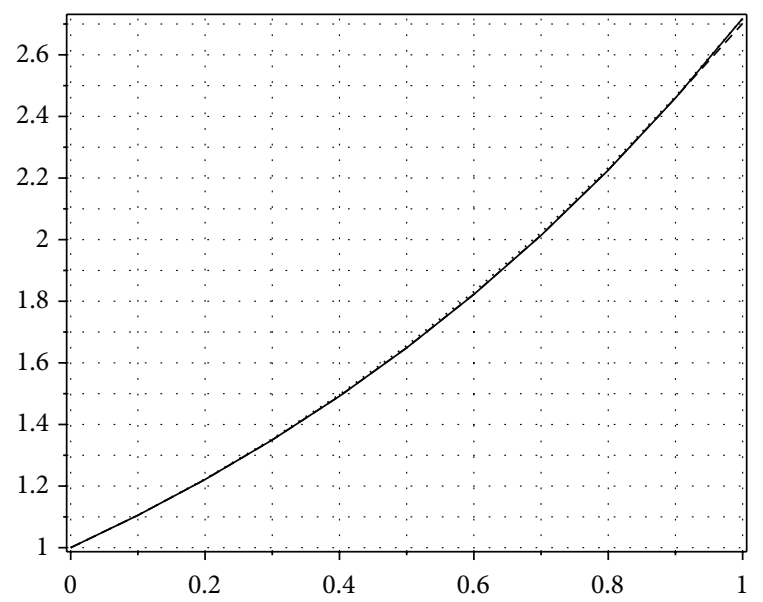

FIGURE 2: Comparison of the analytic and approximate solution of Example 2 by proposed algorithm and [3]. In this figure solid line shows exact solution, dotted lines show approximate solution by proposed algorithm, and dashed lines show the solution obtained by [3].

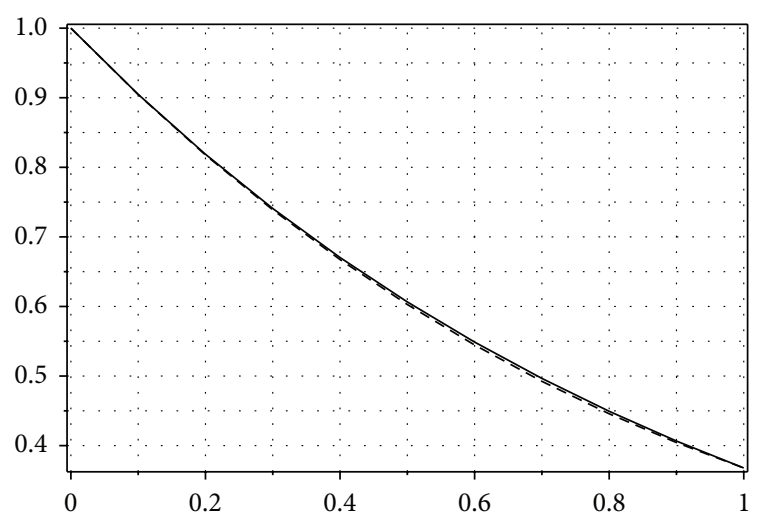

FIGURE 3: Comparison of the analytic and approximate solution of Example 3 by proposed algorithm. In this figure solid line shows exact solution and dashed lines show approximate solution by proposed algorithm.

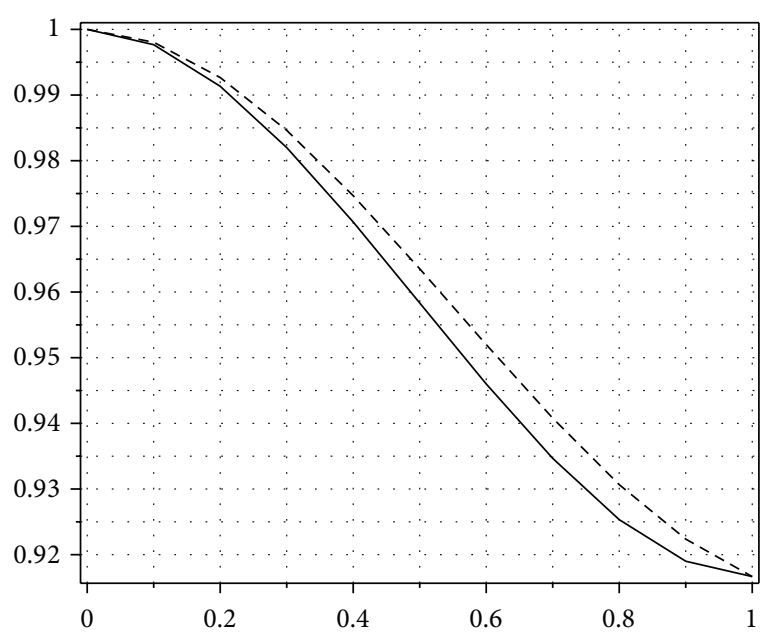

FIGURE 4: Comparison between exact and approximate solutions of Example 4 for $k=0$. Solid line represents exact solution and dash line represents approximate solution.

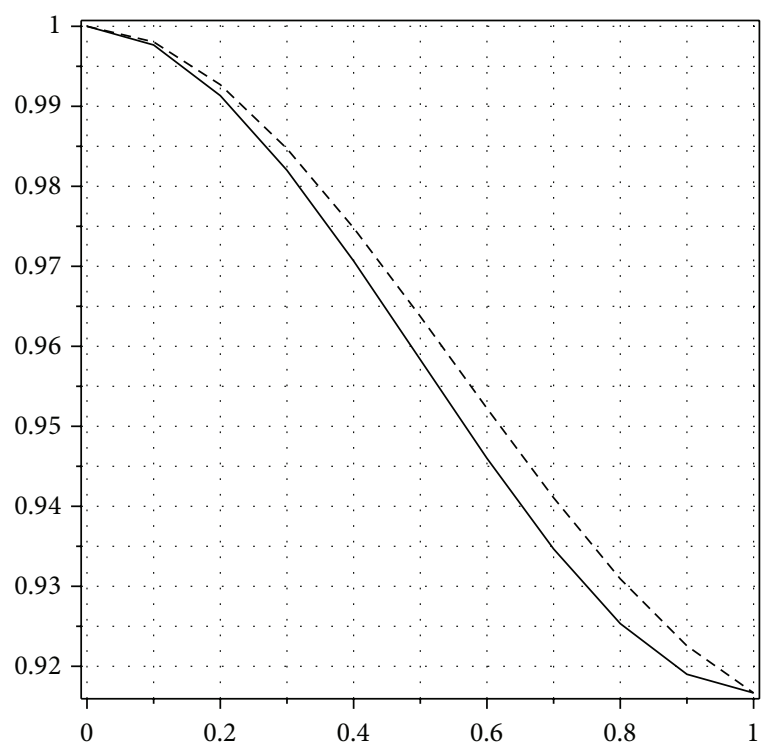

FIGURE 5: Comparison between exact and approximate solutions of Example 4 for $k=1 / 2$. Solid line represents exact solution and dash line represents approximate solution.

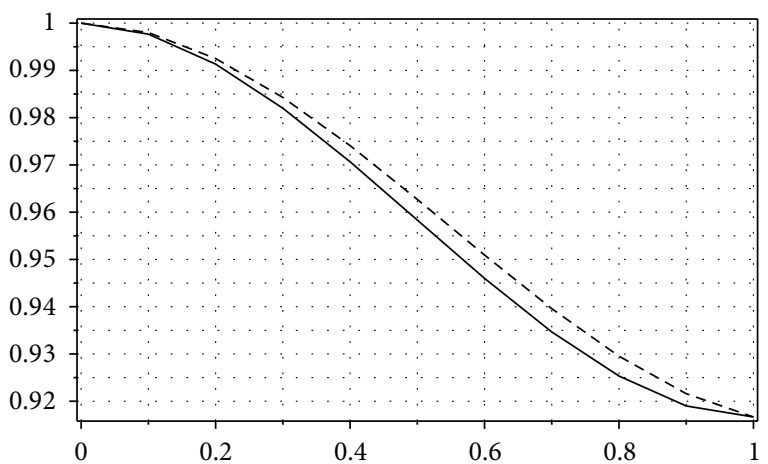

FIgURE 6: Comparison between exact and approximate solutions of Example 4 for $k=2$. Solid line represents exact solution and dash line represents approximate solution. 


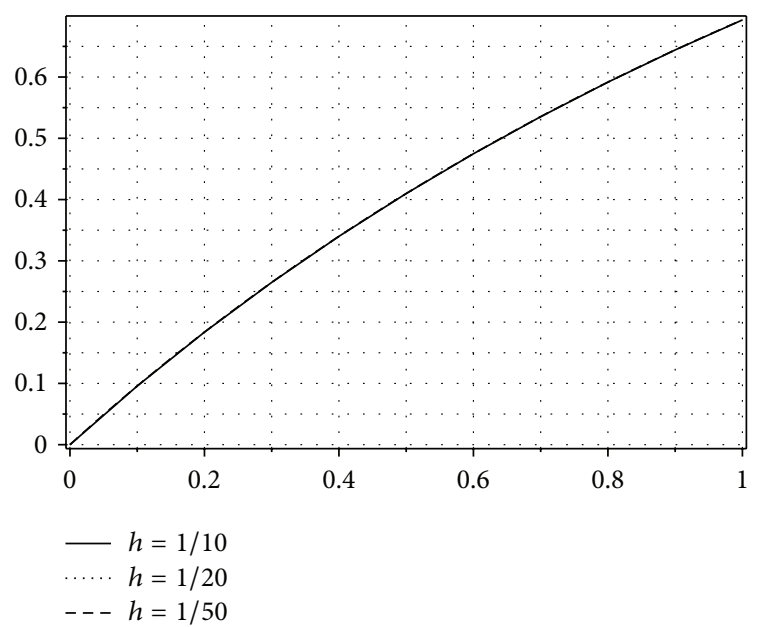

(a)

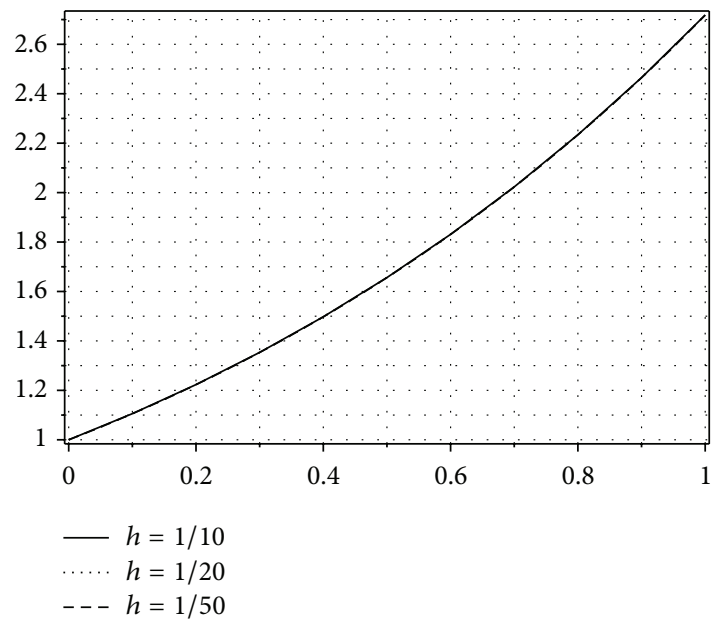

(b)

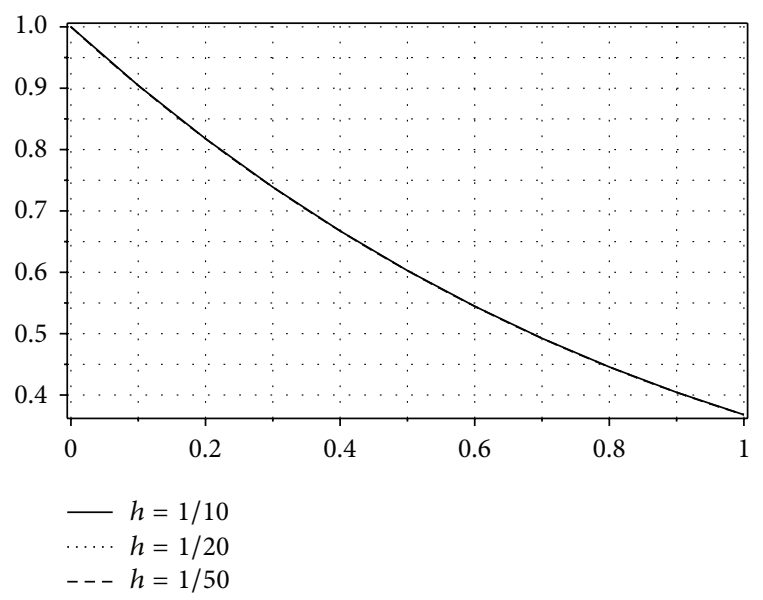

(c)

Figure 7: Approximate solutions of Examples 1, 2, and 3 at different step sizes.

see that step sizes have small effect on the numerical solutions of BVPs.
6.3. Conclusion. In this paper, we have presented subdivision based iterative collocation algorithm for the solution of nonlinear third-order boundary value problems. The proposed algorithm has been applied on different nonlinear third-order boundary value problems. Numerical results show that the accuracy of approximate solution is $O\left(h^{3}\right)$. We have also observed that the accuracy of the solution can be improved by choosing different subdivision schemes with the proper adjustment of boundary conditions. Our proposed algorithm gives better results comparative to the solution obtained by fourth-degree B-spline [5]. The order of approximation by the proposed algorithm and modified Adomian decomposition method [3] is the same.

\section{Competing Interests}

The authors declare that there is no conflict of interests regarding the publication of this paper and regarding the funding that they have received.

\section{Acknowledgments}

This work is supported by NRPU (P. no. 3183) and Indigenous Ph.D. Scholarship Scheme of HEC Pakistan.

\section{References}

[1] F.-I. Haq, I. Hussain, and A. Ali, "A haar wavelets based numerical method for third-order boundary and initial value problems," World Applied Sciences Journal, vol. 13, no. 10, pp. 2244-2251, 2011.

[2] J.-S. Duan and R. Rach, "A new modification of the Adomian decomposition method for solving boundary value problems for higher order nonlinear differential equations," Applied Mathematics and Computation, vol. 218, no. 8, pp. 4090-4118, 2011.

[3] Y. Q. Hasan, "The numerical solution of third-order boundary value problems by the modified decomposition method," Advances in Intelligent Transportation Systems, vol. 1, no. 3, pp. 71-74, 2012.

[4] A. S. Abdullah, Z. A. Majid, and N. Senu, "Solving third order boundary value problem using fourth order block method," Applied Mathematical Sciences, vol. 7, no. 53-56, pp. 2629-2645, 2013.

[5] H. N. Caglar, S. H. Caglar, and E. H. Twizell, "The numerical solution of third-order boundary-value problems with fourthdegree B-spline functions," International Journal of Computer Mathematics, vol. 71, no. 3, pp. 373-381, 1999.

[6] A. H. Bhrawy and W. M. Abd-Elhameed, "New algorithm for the numerical solutions of nonlinear third-order differential equations using Jacobi-Gauss collocation method," Mathematical Problems in Engineering, vol. 2011, Article ID 837218, 14 pages, 2011.

[7] R. Qu and R. P. Agarwal, "Solving two point boundary value problems by interpolatory subdivision algorithms," International Journal of Computer Mathematics, vol. 60, no. 3-4, pp. 279-294, 1996.

[8] R. Qu and R. P. Agarwal, "An iterative scheme for solving nonlinear two-point boundary value problems," International 
Journal of Computer Mathematics, vol. 64, no. 3-4, pp. 285-302, 1997.

[9] G. Mustafa and S. T. Ejaz, "Numerical solution of twopoint boundary value problems by interpolating subdivision schemes," Abstract and Applied Analysis, vol. 2014, Article ID 721314, 13 pages, 2014.

[10] S. T. Ejaz, G. Mustafa, and F. Khan, "Subdivision schemes based collocation algorithms for solution of fourth order boundary value problems," Mathematical Problems in Engineering, vol. 2015, Article ID 240138, 18 pages, 2015.

[11] R. P. Agarwal, "Non-linear two point boundary value problems," F. C. Auluck, FNA, vol. 4, no. 7-8, 1973.

[12] C. Deng and W. Ma, "A unified interpolatory subdivision scheme for quadrilateral meshes," ACM Transactions on Graphics, vol. 32, no. 3, article 23, 2013.

[13] G. Deslauriers and S. Dubuc, "Symmetric iterative interpolation processes," Constructive Approximation, vol. 5, no. 1, pp. 49-68, 1989.

[14] G. Strang, Linear Algebra and Its Applications, Cengage Learning India Private Limited, 4th edition, 2011.

[15] E. Kılıç and P. Stanica, "The inverse of banded matrices," Journal of Computational and Applied Mathematics, vol. 237, no. 1, pp. 126-135, 2013.

[16] L. H. Tanner, "The spreading of silicone oil drops on horizontal surfaces," Journal of Physics D: Applied Physics, vol. 12, no. 9, pp. 1473-1484, 1978.

[17] E. Momoniat, "Numerical investigation of a third-order ODE from thin film flow," Meccanica, vol. 46, no. 2, pp. 313-323, 2011.

[18] B. R. Duffy and S. K. Wilson, "A third-order differential equation arising in thin-film flows and relevant to Tanner's Law," Applied Mathematics Letters, vol. 10, no. 3, pp. 63-68, 1997. 


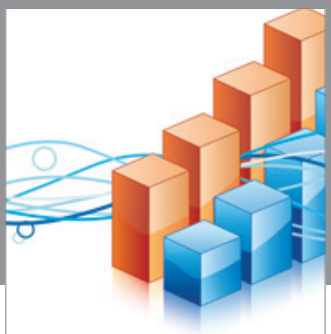

Advances in

Operations Research

vatem alat4

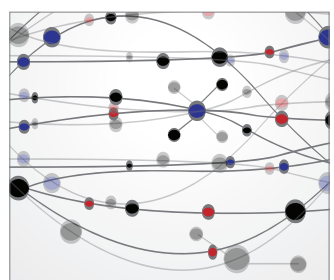

\section{The Scientific} World Journal
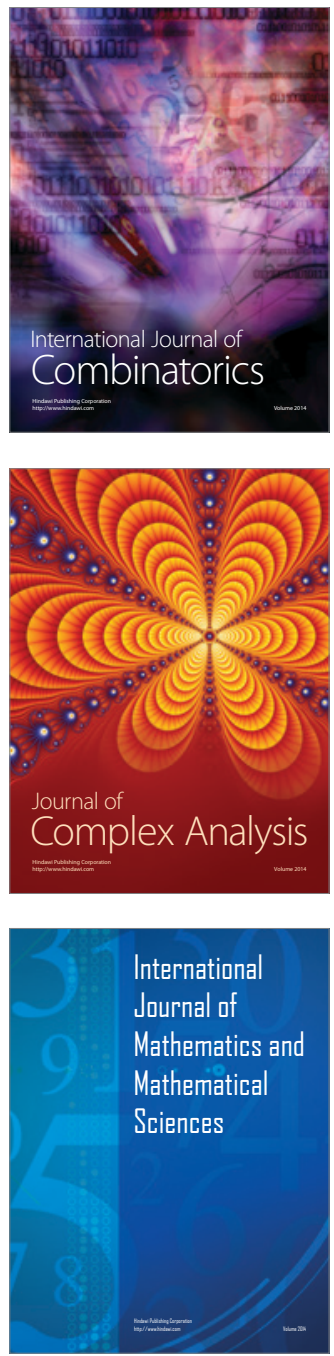
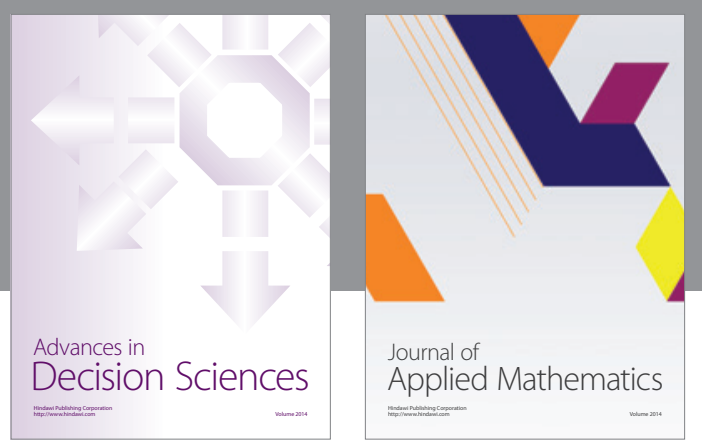

Algebra

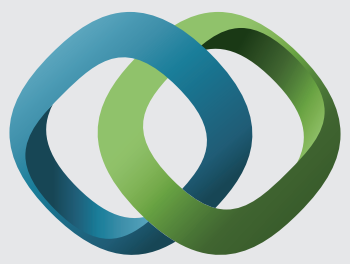

\section{Hindawi}

Submit your manuscripts at

http://www.hindawi.com
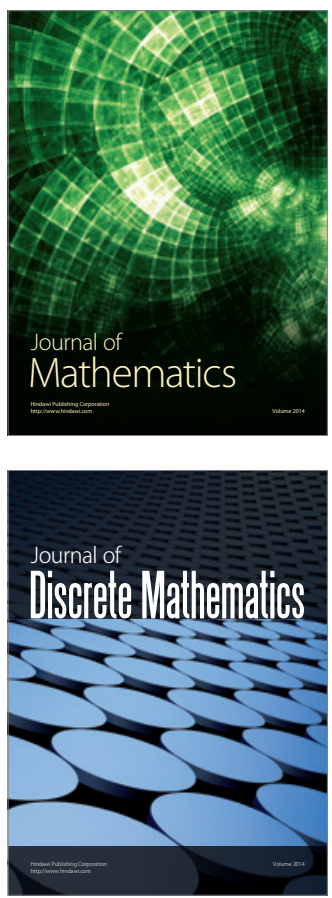

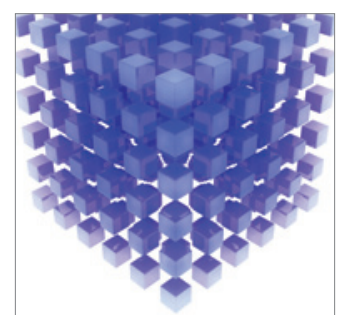

Mathematical Problems in Engineering
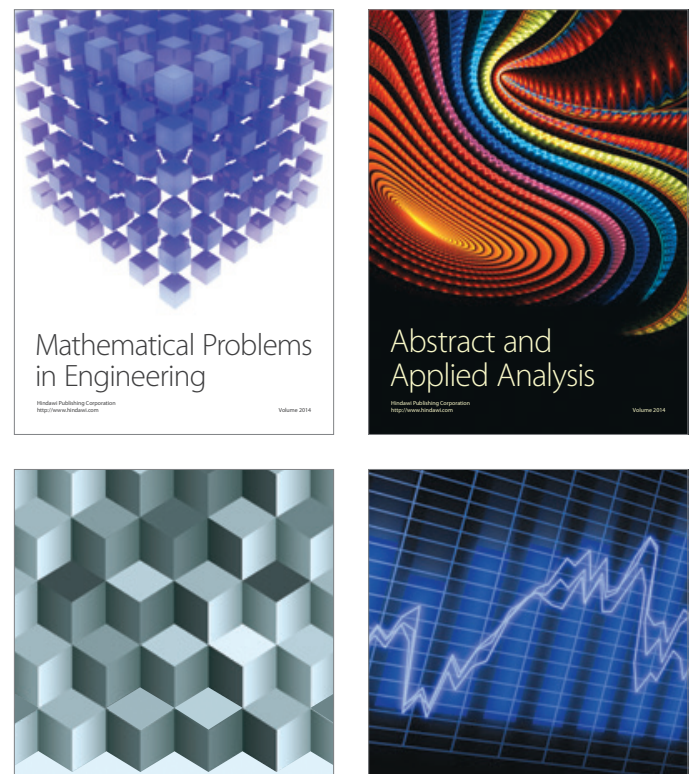

Journal of

Function Spaces

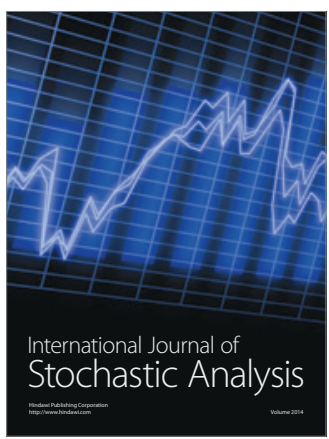

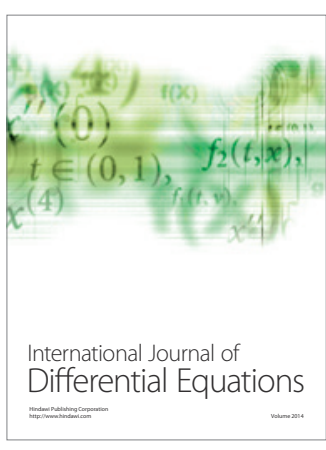
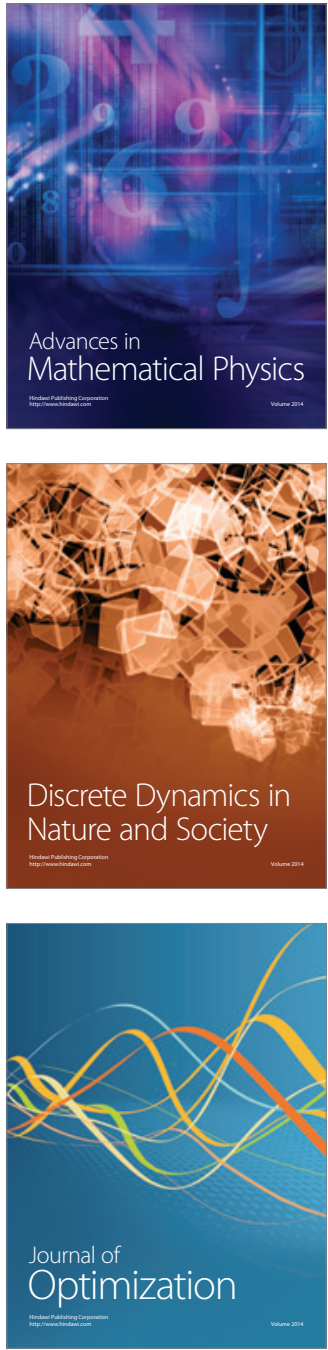